\title{
Teachers' Emotional Labour and Burnout: Does Perceived Organizational Support Matter?
}

\author{
Edith A. Anomneze ${ }^{1}$, Dorothy I. Ugwu ${ }^{2}$, Ibeawuchi K. Enwereuzor ${ }^{1} \&$ Leonard I. Ugwu ${ }^{1}$ \\ ${ }^{1}$ Department of Psychology, University of Nigeria, Nsukka, Nigeria \\ ${ }^{2}$ Department of Health \& Physical Education, University of Nigeria, Nsukka, Nigeria \\ Correspondence: Dorothy I. Ugwu, Department of Health \& Physical Education, University of Nigeria, Nsukka, \\ Nigeria. E-mail: Dorothy.ugwu@unn.edu.ng; ugwudorothy@yahoo.com
}

\author{
Received: July 24, 2015 Accepted: August 11, 2015 Online Published: January 12, 2016 \\ doi:10.5539/ass.v12n2p9 URL: http://dx.doi.org/10.5539/ass.v12n2p9
}

\begin{abstract}
The study investigated the moderating role of perceived organizational support on emotional labour-burnout relation among 323 secondary school teachers in Enugu State, Nigeria. Participants completed the Teacher Emotional Labor Scale (TELS), Survey of Perceived Organizational Support (SPOS), and Maslach Burnout Inventory (MBI). Results showed that surface acting, deep acting, and POS significantly predicted emotional exhaustion. Only deep acting and POS significantly predicted depersonalization whereas surface acting did not. Both the two-way interaction terms between surface acting and POS, and that between deep acting and POS were not significant in predicting either emotional exhaustion or depersonalization.
\end{abstract}

Keywords: emotional labour, burnout, perceived organizational support, teaching profession, teachers

\section{Introduction}

Globally, teachers occupy a central role in the delivery of quality education to students. Unfortunately, there has been increasing evidence to suggest that teachers experience burnout while discharging their duties (e.g., Brouwers, Tomic, \& Boluijt, 2011; Kinman, Wray, \& Strange, 2011). Recently, Schaufeli and Salanova (2014) cited a large epidemiological study that was conducted among 12,000 Dutch employees where it was reported that the highest levels of burnout are found among teachers and those with higher education. In the same vein, Kinman et al. (2011) as well as Mukundan and Ahour (2011) also cited several studies that attest to the fact that the teaching profession is particularly more stressful than the average stress levels of individuals working in other human service-related occupations. This is really worrisome as recent researchers have increasingly considered burnout as a significant workplace strain found to be associated with poor job performance and poor psychological and physical health of employees (Brouwers et al., 2011; Fernet, Guay, Senécal, \& Austin 2012). In elucidating teacher's job burnout, it is probable that the activities students are engaged in during their lessons, the way they interact (which may result to altercation), the time the teacher spends in preparing lessons and marking papers, and the way the classroom is organized can be strenuous to the teacher. This is because a teacher sometime has to be compassionate and open-minded and at other times very stringent in order to avoid risk and detrimental physical contact. In addition, a teacher has to manage students who may be boisterous, noisy, troublesome (Brouwers et al., 2011), engage in disruptive and disrespectful behaviour, and inattentiveness (Fernet et al., 2012). In the long run, it is the students who bear the brunt of the teacher's burnt-out as it may impact negatively on the academic performance of the students.

Research has identified two core dimensions of burnout: emotional exhaustion and depersonalization (Bakker, Demerouti, \& Euwema, 2005; Heuven \& Bakker, 2003; Schaufeli, Bakker, \& Van Rhenen, 2009; Schaufeli \& Taris, 2005). Emotional exhaustion refers to feelings of being emotionally stretched to breaking point and drained of one's emotional resources, while depersonalization involves a negative, uninterested, or overly impersonal attitude or responses to others, especially the recipients of one's services or care (Demerouti, Bakker, \& Leiter, 2014; Maslach \& Jackson, 1981; Schaufeli \& Salanova, 2014). According to Mukundan and Ahour (2011), emotional exhaustion, in the teaching profession, occurs when teachers feel weary and fatigued which manifest when emotional energies are depleted. Consequently, the affected teachers discover that they can no longer give their best to students as they are used to before. And at the end of the day, the teacher may become physically and mentally exhausted (Brouwers et al., 2011) which can result to students' negative reactions and 
attitudes toward the teacher in particular and the learning situation in general. Mukundan and Ahour further state that teachers experience depersonalization or cynicism when they no longer have positive feelings about their students anymore. For example, they start showing signs of cold, callous, negative, and apathetic attitudes toward them and sometimes resort to physically isolating themselves from the students. The lack of interest in teaching, communicating, and conveying the lesson of the day might be warning indications of the burnt-out teachers (Mukundan \& Ahour, 2011).

Several studies have been conducted to understand the antecedents of teachers' job burnout (e.g., Brouwers et al., 2011; Fernet et al., 2012; Kinman et al., 2011). While these studies have greatly enhanced our understanding on how often teachers feel burnt-out, little is however known concerning the intensity of the burnout experienced by teachers in their teaching profession. In other words, the intensity of burnout experienced by teachers has been unduly neglected in previous studies. As such, not much attention has been devoted to how intensely burnout is experienced by teachers, which appear to be an important research area in need of empirical investigation. Therefore, the first aim of the present study is to investigate the intensity of burnout experienced by teachers in the course of discharging their duties. Thus, this study tries to advance the literature on burnout by calling for a paradigm shift from how often teachers experience burnout to the intensity of burnout experienced by teachers, given that previous studies (e.g., Brouwers et al., 2011; Fernet et al., 2012; Kinman et al., 2011) have already established that indeed, teachers often experience burnout in their teaching profession.

An additional common feature for workers in the human service profession such as teaching is that, interacting with people involves emotional labour. Conventionally, researchers on emotions in organizations have devoted their attention on jobs involving emotional expression incorporated into the job role (e.g., the service sector) (Sanz-Vergel, Rodríguez-Muñoz, Bakker, \& Demerouti, 2012). Accordingly, van Gelderen, Konijn, and Bakker (2011) state that emotional labour is especially pertinent for the human service professions, in which regular contact with clients forms an integral element of the job. Consistent with this stance, Schaufeli and Enzmann (1998, p. 124) argue that "the notion of emotional labour is potentially important for our understanding of burnout since it captures an essential aspect of the professional-recipient relationship". Thus, teaching is characterized by intense emotional activity (Fernet et al., 2012); that calls for the successful management of personal emotions and the knack to bring about the desired emotional state in others (Kinman et al., 2011). On this basis, teaching job can be said to be emotionally-laden in many ways.

Unfortunately, emotional labour that teachers perform has not received much research attention (Zembylas, 2003). As yet, there is limited evidence about how the emotional labour involved in the teaching role may undermine the well-being of teachers. Most of what is known has been garnered from reviews, commentaries and ethnographic studies (Chang, 2009), suggesting an existing research void that warrants further investigation. In addition, although there has been a surge of interest in emotional labour and burnout, as they continue to appear as core concepts in recent organizational behaviour studies (e.g., Demerouti et al., 2014; Moon, Hur, \& Jun, 2013; Schaufeli \& Salanova, 2014), these concepts appear to be somewhat in embryonic stage in the Nigerian organizational context. Hence, insight into how emotional labour results in burnout can only enhance the understanding of teacher well-being (Kinman et al., 2011) in the Nigerian organizational context. Therefore, the second aim of this study is to investigate the relationship between teacher's emotional labour and the intensity of burnout they experience.

Next to investigating the emotional labour-burnout relation, the present study also aims to extend burnout research by focusing on the potential moderating role of perceived organizational support (POS) in this relationship. With few exceptions (e.g., Jawahar, Stone, \& Kisamore 2007; Moon et al., 2013; Srivastava, 2011), most previous studies have focused on coworker or supervisor support (e.g., Brouwers et al., 2011). Little is however known concerning whether POS can protect teachers from the negative impact of emotional labour. Accordingly, the third aim of the present study is to examine whether POS helps teachers mitigate the impact of the emotional labour inherent in their job. Because burnout has major significance for both employees and organizations, it is thus crucial to continue searching for mechanisms and strategies by which teachers can reduce the deleterious impacts of emotional labour and burnout. The present study thus, further contributes to the literature by attempting to deepen our understanding of the psychological mechanisms that can explain when and how emotional labour may result to burnout.

\subsection{Theoretical Overview and Hypotheses Development}

The Job Demands-Resources (JD-R) model of burnout (Demerouti, Bakker, Nachreiner, \& Schaufeli, 2001) can provide the basis for explaining how performing emotional labour may lead to burnout and how perceived organizational support (POS) can moderate the emotional labour-burnout relation. At the heart of the JD-R 
model of burnout is the assumption that albeit each occupation may have its own particular work characteristics associated with burnout, it is still possible to model these characteristics in two broad categories: job demands and job resources (Bakker, Demerouti, De Boer, \& Schaufeli, 2003; Demerouti et al., 2001), thus constituting an overarching model that can be applied to various workplaces, irrespective of the particular demands and resources involved.

Job demands refer to those physical, social, or organizational aspects of the job that require sustained physical or mental effort and are therefore associated with certain physiological and psychological costs (Demerouti et al., 2001). Examples are a high work pressure, role overload, emotional demands, and poor environmental conditions (Bakker, Demerouti, \& Verbeke, 2004).

Job resources refer to those physical, psychological, social, or organizational aspects of the job that (a) are functional in achieving work goals, (b) reduce job demands and the associated physiological and psychological costs, or (c) stimulate personal growth and development (Demerouti et al., 2001). Resources may be located at the level of the organization, interpersonal and social relations, the organization of work, and the level of the task (Bakker et al., 2004). In general, job demands and resources are negatively related, since job demands such as a high work pressure and emotionally demanding interactions with clients may rule out the mobilization of job resources (Bakker et al., 2003). Job demands may evoke a strain or health impairment process, whereas job resources stimulate a motivational process (Bakker \& Demerouti, 2007).

Another assumption in the JD-R model is that burnout develops, regardless of the type of job or occupation, when certain job demands are high and when certain job resources are inadequate (Demerouti et al., 2001). Although job demands are not essentially negative, they may nevertheless become job stressors if meeting those demands involves high effort from which the employee has not sufficiently recovered (Sonnentag \& Zijlstra, 2006). In the teaching profession for example, certain occurrences in the classroom such as an overly stubborn and troublesome student who constantly constitutes a nuisance in the class by trying to distract other students, being inattentive, making noise, bullying others, refusing to do assignments and so on, could evoke an emotion (e.g., anger, embarrassment) in the teacher, which may result to emotion-driven behaviours, such as frowning, yelling at the student, or punishing the student. However, in order to comply with the display rules (i.e., emotional job demands) of the school, it may require that the teacher performs emotional labour to regulate his or her own emotion. Thus, the teacher may use surface acting to suppress emotions like frustration, irritation, anger, or tension due to the student's misbehaviour. The teacher may smile even though he or she is depressed, or may try to appear polite even though he or she is very angry with the student. The JD-R model suggests that in the long run, the consequences of sustained suppression of these negative emotions or prolonged performance of emotional labour as part of the demands of the teaching job may lead to burnout over time. In other words, the teacher may feel burnt-out from over diminution of emotional energy that serves as the cost of faking emotion (performing emotional labour) that were not actually felt. In line with this notion, Schaufeli and Taris (2014) asserts that prolonged excessive job demands from which employees do not effectively recover may lead to persistent activation and overtaxing, in the long run resulting in exhaustion - the energetic component of burnout. However, job resources may weaken the negative effect of job demands on exhaustion. This is in accordance with the definition of job resources, which are believed to lessen job demands and the resultant exhaustion (Schaufeli \& Taris, 2014).

The JD-R model suggests that perceived organizational support (POS) as a job resource would alleviate any negative impact emotional labour may have on burnout among teachers. Emotional labour in this sense constitutes job demand since it is expected to be performed as part of the job roles. Thus, when teachers continuously suppress their true emotion by applying emotional labour, over time, they may become burnt-out from such "faking". However, as proposed by the JD-R model, POS as a job resource can mitigate whatever negative impact emotional labour may have on burnout. That is, even if teachers perform emotional labour, it may not lead to burnout for those who perceive that the school values their contribution and cares about their well-being by trying to protect them from any negative impact that may result from performing emotional labour as required by their job. Such organizational support may be in the form of considering the best interests of teachers when making decisions that affects them, showing concern about the teachers' general satisfaction at work, and trying to make the teaching job as interesting as possible.

\subsection{Emotional Labour and Burnout}

The concept of emotional labour was first introduced by Hochschild (1983) based on her studies of flight attendants, but ensuing research has found emotional labour to be usual in a number of human service occupations and a sizeable predictor of strain in the workplace (Brotheridge, 2006). Hochschild conceptualizes 
emotional labour as the expressing and regulating of affect or feelings in the workplace in order to conform to professional and organizational rules. Display rules as they are called, are principles that govern what emotions should be revealed to and hidden from others at work (Byrne, Morton, \& Dahling, 2011). These rules typically forms part of an organization's policy, clarifying which emotions the organization considers apt to show to clients (van Gelderen et al., 2011) or implicit and internalized via experience and socialization into a profession and/or a particular organization (Byrne et al., 2011).

Two emotional labour strategies are considered in the emotional labour literature (e.g., Brotheridge, 2006; Hochschild, 1983; Moon et al., 2013) to constitute the core dimensions of the construct. They are: surface acting and deep acting. Whereas the first category entails simulating or faking emotions not in fact felt, the second category involves attempting to actually feel the opposite emotions. More to the point, surface acting entails faking or pretending to have the required emotional display without changing one's internal feelings which is sometimes referred to as acting in bad faith because it involves simply putting on an inauthentic act (Grandey, 2000). This implies that the employees will only adjust their emotional expressions while their inner feelings remain unadjusted in order to conform to organizationally required emotion display rules (Lee, Hung, \& Huang 2012). In contrast, the second strategy, deep acting, entails bringing forth the required emotional display by working to change one's internal feelings. Deep acting takes place when the individual consciously strives to adjust his or her feelings so that they are in accordance with the desired emotional expression (Grandey, 2000). The result is a natural emotional display that is consistent with one's feelings and the obligations of the job. This type of emotional labour is referred to as acting in good faith since the created display is authentic and genuine (Grandey, 2000). According to Hochschild (1983), whether surface acting or deep acting, both processes require effort and this effortful activity of managing emotions has detrimental consequences for employees and leads to experience of repeated stress, alienation and burnout.

According to Hebson, Earnshaw, and Marchington (2007), teachers are increasingly required to manage their emotions in like manner as employees in the service sector. They are expected to express different emotions during their interactions with students. They have to navigate between keeping a certain emotional distance or appear indifferent toward their students to safeguard a professional attitude on the one hand, and showing a sensitive, empathetic attitude on the other hand. When the teacher experiences a large discrepancy or dissonance between felt emotions and expected displays, the likelihood for impulsively expressing what one feels reduces and the need to act (whether deep or surface) increases accordingly. Therefore, emotion regulation will drain employee's emotional resources, which, in turn will result in more burnout complaints (e.g., physical fatigue, emotional exhaustion, cognitive weariness) (Bakker \& Heuven, 2006). Consistent with this notion, Kinman et al. (2011) argue that "Sustained emotional labour may lead to teachers depersonalizing their pupils, resulting in less sympathetic and more cynical attitudes towards them" (p. 844).

Researchers (e.g., Bakker \& Heuven, 2006) contend that the regulation of emotions as necessary job role may be stressful and detrimental to health. In essence, there is considerable evidence that show that emotional labour can undermine employees' well-being, as psychological effort is repeatedly required to regulate emotions in order to comply with organizational or professional rules (Grandey, 2000). For example, Heuven and Bakker (2003) found that the structural discrepancy between inner feelings and the positive emotional display in the job of cabin attendants was, more than quantitative job demands and lack of job control, the main predictor of burnout complaints. In a related study, Bakker and Heuven (2006) investigated the notion that emotionally demanding interactions with recipients may result in job burnout and impaired performance through the mediation of emotional dissonance among nurses and police officers. They found that emotional job demands positively predicted exhaustion and cynicism through their influence on emotional dissonance, and that emotional dissonance was negatively related to in-role performance through its relationship with burnout only for the police sample but not for the nurse sample used in their study. For the nurse sample, burnout fails to mediate the relations between emotional dissonance and performance.

Research has further illuminated the relationship between emotional labour and burnout among teachers. For example, Kinman et al. (2011) explored the relationship between emotional labour, burnout, and job satisfaction among secondary school teachers in the United Kingdom. The results showed, among others, a significant positive association between emotional labour and two dimensions of burnout: emotional exhaustion and depersonalization. An important point to note however in their study is that while burnout was gauged as a multidimensional construct, emotional labour was gauged with a one-dimensional scale. Thus, the unique impact that different facets of emotional labour could have on burnout dimension was not ascertained. In similar fashion, Chang and Chiu (2009) conducted a study in which they examined the relationship between emotional labour and employee exhaustion among flight attendants in the airline industry. Although Chang and Chiu found that 
emotional labour was positively associated with emotional exhaustion, like Kinman et al. (2011), they added the two types of emotional labour strategies together without clear distinction, thereby making it difficult to determine how the surface and deep acting strategies affect emotional exhaustion of flight attendants respectively. It is also unclear how flight attendants use different emotional labour strategies to express the organizationally desired emotions.

Other studies have however indicated that surface and deep acting strategies have different outcomes associated with using them in relation to the manifestation of emotional exhaustion and depersonalization aspects of burnout. Moon et al.'s (2013) study serve as an exemplar of such studies that offer relevant insight in this regard. To this end, Moon et al. examined the supposition that surface acting and deep acting would be differentially related to emotional exhaustion among a sample of flight attendants in South Korea. Consistent with their expectation, surface acting was positively associated with emotional exhaustion, whereas deep acting was negatively associated with emotional exhaustion.

Based on the preceding discussion, we pose the following hypotheses:

Hypothesis 1a: Surface acting will positively predict emotional exhaustion.

Hypothesis 1b: Deep acting will negatively predict emotional exhaustion.

Hypothesis 1c: Surface acting will positively predict depersonalization.

Hypothesis 1d: Deep acting will negatively predict depersonalization.

\subsection{Perceived Organizational Support (POS) as a Moderator}

Perceived organizational support (POS) generally refers to the belief that employees form concerning the degree to which the organization in which they work for fulfils their socio-emotional needs, values their contributions and its readiness to reward the same, and cares about their wellbeing (Eisenberger, Huntington, Hutchison \& Sowa, 1986; Rhoades \& Eisenberger, 2002). POS is thought to develop over time through multiple interactions between employees and their employers and to reflect the degree to which employees perceive that their work organization is committed to them (Rhoades \& Eisenberger, 2002). Hence, since POS engenders one's sense of commitment to care about the organization's welfare based on the reciprocity norm (e.g. Eisenberger et al., 1986), it may affect the decision-making of teachers' emotional regulation strategies. Whereas actual supportive interactions are objective in nature, the perception of being supported relies on the sensitivity of the individual involved, which is subjective in terms of quality (Doeglas et al., 1996).

Eisenberger et al. (1986) point out that POS would be impacted upon by different parts of employee's treatment by the organization and would, in turn, determine the employee's interpretation of organizational intentions behind such treatment. According to Eisenberger et al., it means that there would be a kind of agreement in the extent of support that the employee would expect of the organization in an array of circumstances, such as the organization's possible reactions to the employee's future illnesses, mistakes, and superior performance, and the organization's wish to pay a reasonable salary and make the employee's job worthwhile and appealing. In other words, employees' perception about organizational attitude regarding their support is contingent on the organization's caring activities such as rewarding employees' contributions, showing concern about employee well-being programmes, and opportunities for employees to participate in key organizational decisions.

For teachers, the school serves as an important source of socio-emotional resources, such as respect and caring, and tangible benefits, such as salaries and medical benefits. Being regarded highly by the school will help to meet teachers' supportive need. Positive valuation by the school also provides an indication that increased effort will be acknowledged and rewarded. They therefore take an active interest in the regard with which they are held by their employer (Srivastava, 2011).

From an organizational perspective, social support has regularly been one of the primary remedies to buffer the adverse relationship between emotional labour and burnout. For instance, high levels of POS may reduce the deleterious impact of teachers' emotional labour because schools that care about their employees' well-being are more likely to reduce unnecessary work complications and distractions for their teachers that may be inimical in successful accomplishment of role task. Accordingly, Grandey (2000) argue that employees who perceive high coworker and supervisor support in the workplace are likely to be less affected by the negative effects of emotional labour. Grandey further contends that support from supervisors may decrease emotional labour by creating a positive work environment in which it is easier for employees to feel and express the positive emotions that are expected by their organization. Thus, there are strong grounds to believe that POS is a probable moderator of emotional labour and burnout in the teaching profession. Grandey stressed that first, employees who experience more compassionate interpersonal relationships in their workplace may find gratifying the 
emotional demands of their job role to be less burdensome. Second, employees who feel more supported might report lower levels of emotional labour as the suitable emotional response emanates more impulsively. Third, the capability to reveal emotional dealings and exact feelings in a supportive work milieu might assist employees build up more successful coping strategies that protect them against health risks.

Similarly, Bakker et al. (2005) contend that if there is a high quality relationship with a person's supervisor, then the influence of job demands on burnout, may be lessened since leaders' gratitude and support can put demands in another perspective. Invariably, the lack of social support may impair or impact negatively on a person's psychological well-being either directly or indirectly since the person lacks the necessary resources to cope with job demands (Bakker et al., 2005). Therefore, POS may reduce the harmful effects of burnout emanating from emotional labour while performing the job. POS can help teachers to cope with stressors and strains because employees with considerable workplace social support are less likely to experience exhaustion (Hobfall, 2001).

Substantial body of research supports the idea that POS moderates the relationship between emotional labour and burnout. For example, Kinman et al. (2011) examined whether workplace social support moderated any relationships found between emotional labour and burnout among teachers working in secondary schools in the UK. They found that teachers who reported higher levels of workplace social support tended to report less emotional labour. This suggests that workplace social support somehow buffer the negative impact of emotional labour on teachers. On their part, Brouwers et al. (2011) contend that when attempting to explain burnout, it is reasonable that workload and amount of control differ very much from one group of subject teachers to the next. Specifically, Brouwers et al. were interested in knowing whether perceived severe job demands in combination with perceived lack of control on the job and perceived lack of social support from colleagues, principals and managers could increase the level of burnout reported by Physical Education (PE) teachers. Of interest in their findings herein was that colleague support had a moderating effect on the relationship between job demands and the personal accomplishment dimension of burnout, whereas managerial support had a moderating effect on self-efficacy beliefs concerning teachers' influence on job demands.

Ample numbers of studies have also been conducted outside the teaching profession concerning the role of social support in mitigating the harmful impact of job stressors on employees' health outcomes. One of such studies comes from Ogińska-Bulik (2005) who investigated the impact of experienced job stress and personal and social resources (e.g., sense of coherence, self-esteem, self-efficacy, dispositional optimism and social support) on health outcomes among men employed in the uniformed professions (policemen, firefighters, prison officers, security guards, and city guards). Interestingly, the results showed among others, that social support moderated the relations between both job stress perception and health status. High level of perceived social support reduced the sense of stress at work and enhanced the sense of health. In addition, Jawahar et al. (2007) unearthed further evidence concerning the link between role conflict, a type of job stressor and burnout. Jawahar et al. examined the direct as well as the moderating effects of political skill and POS on the relationship between role conflict and burnout among a sample of professional employees comprising of programmers, software and hardware engineers, marketing specialists, and managers in the United States. Interestingly, they found that POS was negatively related to emotional exhaustion, and depersonalization. Perceived role conflict and POS interacted to influence emotional exhaustion, such that the relationship between role conflict and emotional exhaustion was weaker at higher levels of POS. That is, high levels of support had a buffering effect and mitigated the negative effects of role conflict on emotional exhaustion. However, contrary to their expectation, POS failed to moderate the relations between perceived role conflict and depersonalization. Lee et al. (2012) also found that organizational support was positively related to deep acting but negatively related to surface acting facet of emotional labour. Organizational support moderated the relationship between job enjoyment and surface acting such that those with higher organizational support engage in lesser surface acting than those with lower organizational support. Also, the positive relationship between job enjoyment and deep acting was stronger for those with higher organizational support than those with lower organizational support. However, organizational support did not moderate the relationship between job enjoyment and expression of naturally felt emotion.

More recently, research in the airline industry has also illuminated the mechanism through which emotional labour can relate to burnout. For example, Moon et al. (2013) examined the moderating role of POS in the relationship between emotional labour (surface acting or deep acting) and emotional exhaustion among flight attendants in South Korea. Moon et al. found that POS had a significantly positive effect on deep acting, but against expectations, no significant negative effect on surface acting. Furthermore, POS served as a moderator on both the relationship between deep acting and emotional exhaustion and between surface acting and emotional exhaustion as expected. Specifically, deep acting had a larger influence on emotional exhaustion for flight attendants with higher POS than for those with lower POS. Also, surface acting had larger influence on 
emotional exhaustion for flight attendants with lower POS than for those with higher POS.

In sum, the literature has shown that support from various significant people and the organization at large can help to mitigate the harmful effects of emotional labour on burnout. In this regard, we hypothesize that:

Hypothesis 2a. Perceived organizational support will negatively predict emotional exhaustion.

Hypothesis 2b. Perceived organizational support will negatively predict depersonalization.

Hypothesis 3a. Perceived organizational support will moderate the relationship between surface acting and emotional exhaustion such that the positive relationship between surface acting and emotional exhaustion will be stronger for teachers with low perceived organizational support.

Hypothesis 3b. Perceived organizational support will moderate the relationship between deep acting and emotional exhaustion such that the negative relationship between deep acting and emotional exhaustion will be stronger for teachers with high perceived organizational support.

Hypothesis 3c. Perceived organizational support will moderate the relationship between surface acting and depersonalization such that the positive relationship between surface acting and depersonalization will be stronger for teachers with low perceived organizational support.

Hypothesis 3d. Perceived organizational support will moderate the relationship between deep acting and depersonalization such that the negative relationship between deep acting and depersonalization will be stronger for teachers with high perceived organizational support.

\section{Method}

\subsection{Procedure and Participants}

Three hundred and twenty three (323) teachers from three secondary schools located within Nsukka, Enugu State of Nigeria, participated in the study. Of these participants, $146(45.2 \%)$ were male and 177 (54.8\%) were female. Concerning marital status, $207(64.1 \%)$ were single whereas $116(35.9 \%)$ were married. Their average organizational tenure was 6.17 years $(S D=6.02)$, and their average age was 35.83 years $(S D=9.41)$. All the participants have worked for at least six months in their current job position to ensure that they would be able to determine the intensity of burnout they experience in their teaching job. Prior to the distribution of our survey, we sought and obtained the permission of the principals of each of the schools that participated in our study through a letter that explained the purpose of our study. Thereafter, teachers who were available and volunteered to participate were handed the surveys to complete during the period of their long break. A total of 360 surveys were distributed to the teachers. However, it was not until after three days that we were able to collect the completed and returned survey back from the participants. Out of these 360 surveys, only 323 were used for data analyses following the removal of incomplete and/or improperly filled ones, which represents $89.72 \%$ response rate.

\subsection{Measures}

\subsubsection{Emotional Labour}

Emotional labour was assessed with the Surface Acting and Deep Acting subscales of Çukur's (2009) Teacher Emotional Labor Scale (TELS) which was specifically designed to measure emotional labour that teachers experience in the course of their interactions with students, coworkers and supervisors while discharging their duties. Both subscales contain five items each. Ratings were made using a 5-point scale, ranging from 1 (not at all) to 5 (very true). Items on both the Surface Acting and Deep Acting subscales of the TELS were slightly modified in the present study such that the terms 'your' was replaced with 'my', while 'you' was replaced with 'I' or 'me', in order to refer more directly to the particular teacher responding to the items. Sample items include: "I try to control my feelings to have emotions I need to display for my job when sharing sad news with students", and "I try to put an effort to actually feel the emotion I need to display when discussing frequently with students about grades", for the Surface Acting and Deep Acting subscales, respectively. Cronbach's alpha $(\alpha)$ of .73 and .72 were obtained for the Surface Acting and Deep Acting subscales of the TELS, respectively, in the present study. Higher scores on either of these subscales indicate that the teacher made greater use of surface acting or deep acting in the process of discharging his or her duties.

\subsubsection{Perceived Organizational Support}

Perceived organization was measured with the short, 16-item version of the original 36-item version of Eisenberger et al.'s (1986) Survey of Perceived Organizational Support (SPOS). The SPOS was designed to assess the degree to which individuals believe that their organization cares about their well-being. This short 
version comprises of the 16 items with the highest factor loadings on the 36-item SPOS that its developers adopted as the short version. The items were originally rated on a 7-point scale with a response format ranging from 1 (strongly disagree) to 7 (strongly agree). However, "to make response easier, a 5-point Likert response format was adopted instead of the 7-point used in the initial study" (Onyishi, 2006, p.42) for the SPOS which now ranges from 1 (strongly disagree) to 5 (strongly agree). The scale contains both positively and negatively worded items. Sample items include: "The organization really cares about my well-being", and "The organization cares about my opinions." Cronbach's $\alpha$ coefficient of .78 was obtained in the present study for the 16-item version of the SPOS. Higher scores on the SPOS reflect greater perception of organizational support.

\subsubsection{Burnout}

Burnout was measured with the Emotional Exhaustion and Depersonalization subscales of the Maslach Burnout Inventory (MBI) (Maslach \& Jackson, 1981). Whereas the Emotional Exhaustion subscale contains nine items that assess the feelings of being emotionally drained or overextended (e.g., "I feel used up at the end of the workday"), the Depersonalization subscale contains five items that evaluate the feelings of impersonal response toward people (e.g., "I've become more callous toward people since I took this job"). Each statement on these subscales can be rated either based on frequency or intensity of burnout experienced by the respondents. However, in line with the first aim of our study, we opted for the intensity response format. In the original intensity response format, respondents are required to respond to the statements of the Emotional Exhaustion and Depersonalization subscales by using a scale that ranges from 0 (never) to 7 (major, very strong). However, in order to make response easier, a 6-point response format ranging from 0 (never) to 5 (major, very strong) was adopted for these subscales. In addition, in the Emotional Exhaustion and Depersonalization subscales of the MBI, we decided to replace the term 'recipients' with the term 'students', in order 'to refer to the particular people for whom the subject provided service" for (Maslach \& Jackson, 1981, p. 100). This is consistent with previous research that has also done likewise (e.g., Kinman et al., 2011). Higher scores indicate higher levels of emotional exhaustion and depersonalization.

\section{Results}

The data obtained from respondents were subjected to statistical analyses by computing the descriptive statistics and correlations among the study variables (see Table 1). Next, two different Moderated Hierarchical Multiple Regression, were used to test the hypotheses. In the first Regression, emotional exhaustion was the criterion variable while depersonalization was the second criterion variable. The same procedure was followed in entering data for both the first and second Regression. Gender, marital status, organizational tenure, and age were entered as control in the first step of each Regression equation in order to prevent any possible impact they may have on the dependent variable. In the second step, surface acting and deep acting were entered as a block to ascertain whether they will significantly account for variance in the criterion variable (see Table 2). In the third step, perceived organizational support (POS) was entered, followed by the two-way interaction terms between surface acting and POS in the fourth step, and lastly, the two-way interaction terms between deep acting and POS was entered in the fifth step.

3.1

Table 1. Descriptive statistics, Cronbach's $\alpha$, and correlations among the study variables

\begin{tabular}{lllllllllllll}
\hline & Variable & $M$ & $S D$ & 1 & 2 & 3 & 4 & 5 & 6 & 7 & 8 & 9 \\
\hline 1 & Gender & .55 & .50 & - & & & & & & & & \\
2 & Marital status & .36 & .48 & $-.12^{*}$ & - & & & & & & & \\
3 & Organizational tenure & 6.17 & 6.02 & $-.20^{* * *}$ & $.49^{* * *}$ & - & & & & & & \\
4 & Age & 35.83 & 9.41 & $-.13^{*}$ & $.53^{* * *}$ & $.68^{* * *}$ & - & & & & & \\
5 & Surface acting & 15.86 & 4.00 & -.05 & -.05 & .01 & .03 & $(.73)$ & & & & \\
6 & Deep acting & 16.36 & 4.28 & -.03 & -.08 & -.04 & -.06 & $.56^{* * *}$ & $(.72)$ & & & \\
7 & POS & 49.12 & 8.38 & -.05 & -.05 & -.02 & -.10 & $.11^{*}$ & $.13^{*}$ & $(.78)$ & & \\
8 & EE & 15.85 & 8.96 & -.03 & $.13^{*}$ & $.13^{*}$ & $.12^{*}$ & $.13^{*}$ & $-.12^{*}$ & $-.14^{*}$ & $(.84)$ & \\
9 & Depersonalization & 7.38 & 6.53 & -.03 & $.11^{*}$ & .09 & .05 & -.108 & $-.11^{*}$ & $-.24^{* * *}$ & $.47^{* * *}$ & $(.84)$ \\
\hline
\end{tabular}

Note. $N=323$, Cronbach's $\alpha$ for applicable scales are reported in parenthesis along the diagonal, $*=p<.05$ (2-tailed), ${ }^{* *}=p<.01$ (2-tailed), $* * *=p<.001$ (2-tailed). Gender was coded $0=$ male, $1=$ female; marital status was coded $0=$ single, $1=$ married; age and organizational tenure 
Results in Table 1 indicate that gender was not significantly related to emotional exhaustion, whereas marital status $(r=.13, p<.05)$, organizational tenure $(r=.13, p<.05)$, age $(r=.12, p<.05)$, surface acting $(r=.13, p$ $<.05)$, were significantly related to emotional exhaustion in positive direction. However, deep acting $(r=-.12, p$ $<.05)$ and POS $(r=-.14, p<.05)$ were significantly related to emotional exhaustion in negative direction. Specifically, those who were married are more likely to experience emotional exhaustion than those who were single. Furthermore, gender, organizational tenure, age, and surface acting, were not significantly related to depersonalization, whereas, marital status $(r=.11, p<.05)$ and emotional exhaustion $(r=.47, p<.001)$ were significantly related to depersonalization in positive direction. Specifically, those who were married are more likely to experience depersonalization than those who are single. Meanwhile, deep acting $(r=-.11, p<.05)$ and $\operatorname{POS}(r=-.24, p<.001)$ were significantly related to depersonalization in negative direction.

\section{2}

Table 2. Summary of moderated hierarchical multiple regression of predictors of emotional exhaustion and depersonalization

Emotional exhaustion

Depersonalization

\begin{tabular}{ccccccccccc}
\hline Variable & Step 1 & Step 2 & Step 3 & Step 4 & Step 5 & Step 1 & Step 2 & Step 3 & Step 4 & Step 5 \\
& $\beta$ & $\mathrm{B}$ & $\beta$ & $\beta$ & $\beta$ & $\beta$ & $\mathrm{B}$ & $\mathrm{B}$ & $\beta$ & $\beta$ \\
\hline Gender & -.00 & .00 & -.00 & -.00 & .01 & -.01 & -.01 & -.03 & -.03 & -.03 \\
Marital status & .08 & .09 & .09 & .08 & .08 & .10 & .09 & .09 & .09 & .09 \\
Organizational tenure & .07 & .07 & .08 & .08 & .07 & .07 & .07 & .09 & .09 & .09 \\
Age & .02 & .02 & .01 & .01 & .00 & -.06 & -.05 & -.09 & -.09 & -.09 \\
Surface acting & & $.14^{*}$ & .15 & .14 & .15 & & -.06 & -.05 & -.05 & -.05 \\
Deep acting & & $-.16^{*}$ &.-15 & -.15 &.-16 & & $-.19^{* *}$ & -.19 & -.19 & -.20 \\
POS & & & $-.19^{*}$ & -.20 & -.20 & & & $-.23^{* * *}$ & -.24 & -.24 \\
Surface acting X POS & & & & -.03 & .02 & & & & .02 & .00 \\
Deep acting X POS & & & & & -.10 & & & & & .02 \\
Adjusted $R^{2}$ & .010 & .005 & .008 & .005 & .009 & .003 & .011 & .061 & .058 & .055 \\
$\Delta R^{2}$ & .023 & $.038^{*}$ & $.059^{*}$ & .001 & .006 & .015 & $.036^{* *}$ & $.052^{* * *}$ & .000 & .000 \\
$F$ & 1.85 & 1.28 & 1.37 & 1.22 & 1.32 & 1.22 & 1.58 & 3.96 & 3.47 & 3.09 \\
$\Delta F$ & 1.85 & $14.05^{*}$ & $17.92^{*}$ & .19 & 2.09 & 1.22 & $14.29^{* *}$ & $17.74^{* * *}$ & .07 & .14 \\
\hline
\end{tabular}

Note. $*=p<.05, * *=p<.01, * * *=p<.001$.

Results in Table 2 indicate that the first Moderated Hierarchical Multiple Regression in which emotional exhaustion was the criterion variable, show that the control variables (gender, marital status, organizational tenure, and age) entered in step 1 of the equation were unable to explain any significant variance in emotional exhaustion either as a block or as individual variables. In step 2, when surface acting and deep acting were entered as a block, they added $3.8 \%$ variance in emotional exhaustion $\left(\Delta R^{2}=.038, p<.05\right)$, with both surface acting $(\beta=.14, p<.05)$ and deep acting $(\beta=-.16, p<.05)$ contributing significantly in positive and negative direction, respectively, which confirm Hypothesis $1 \mathrm{a}$ and $1 \mathrm{~b}$. The inclusion of POS in step 3 of the equation explained $5.9 \%$ variance in the prediction of emotional exhaustion $\left(\beta=-.19, \Delta R^{2}=.059, p<.05\right)$, this also confirms Hypothesis 2a. The entry of the two-way interaction terms at step 4 revealed an insignificant two-way interaction between surface acting and POS. Furthermore, the entry of the two-way interaction terms between deep acting and POS in step 5 also yielded an insignificant interaction. Therefore, Hypotheses $3 \mathrm{a}$ and $3 \mathrm{~b}$ were not confirmed.

In the second Moderated Hierarchical Multiple Regression in which depersonalization was the criterion variable, the control variables (gender, marital status, organizational tenure, and age) entered in step 1 of the equation failed to make any statistically significant contribution to the prediction of depersonalization either as a block or as individual variables. When surface acting and deep acting were included as a block at step 2 of the equation, 
they were able to account for $3.6 \%$ variance in depersonalization, with only deep acting $(\beta=-.19, p<.01)$ making significant negative contribution to the prediction of depersonalization while surface acting did not $(\beta=$ $-.06, \mathrm{~ns})$. Therefore, Hypothesis $1 \mathrm{~d}$ was confirmed while Hypothesis $1 \mathrm{c}$ was not confirmed. The entry of POS in step 3 of the equation was able to explain significant $5.2 \%$ variance in the prediction of depersonalization ( $\beta=$ $-.23, \Delta R^{2}=.052, p<.001$ ), which confirms Hypothesis $2 \mathrm{~b}$. In step 4 , the addition of the two-way interaction terms between surface acting and POS was not significant. Also, the entry of the two-way interaction terms between deep acting and POS was not significant; hence, Hypothesis $3 \mathrm{c}$ and $3 \mathrm{~d}$ were not confirmed.

\section{Discussion}

This study has added to the growing body of knowledge concerning the emotional labour performed by teachers and the potential impact on burnout, as well as the potential moderating role of perceived organizational support (POS). The results obtained are in accordance with the predictions of Hypotheses $1 \mathrm{a}$ and $1 \mathrm{~b}$, which revealed that both surface acting and deep acting were positively and negatively predictive of burnout, respectively. This indicates that teachers who reported using more surface acting aspect of emotional labour were more emotionally exhausted, whereas those who performed more deep acting were less emotionally exhausted. As such, given that surface acting has to do with acting in bad faith because it involves simply putting on an inauthentic act (Grandey, 2000), a positive association between surface acting and emotional exhaustion was expected. Nevertheless, as it has been indicated that teachers deem emotional labour to be an intrinsic part of their work (Sutton, 2004), negative association between deep acting and emotional exhaustion was expected, since deep acting involves conscious adjustment of feelings so that they are in concurrence with the desired emotional expression. The findings provide empirical support for previous observations that suggest that not all dimensions of emotional labour have potentially adverse consequences for employees. As in the current study, Moon et al. (2013), for example, provided evidence for the supposition that the impact of emotional labour may not be entirely negative for employees. Specifically, Moon et al. found that surface acting and deep acting was positively and negatively associated with burnout, respectively. The findings are, however, somewhat at variance with that of Kinman et al. (2011) who found that emotional labour was positively associated with emotional exhaustion and depersonalization dimensions of burnout among secondary school teachers. A potential reason for this could be because Kinman et al. measured emotional labour as a one-dimensional construct, thereby obscuring the unique impact that surface acting and deep acting can have on different dimensions of burnout.

The results also provided support for Hypotheses 1d as deep acting significantly predicted lower levels of depersonalization. The finding that deep acting negatively predicted depersonalization suggests that teachers who engage more in deep acting in their job were less likely to exhibit cynical attitudes towards their students. However, Hypothesis 1c was not confirmed as the results revealed that surface acting did not significantly predict depersonalization. Therefore, the findings suggest that surface acting does not contribute to depersonalization. These findings are somewhat at variance with that reported by Kinman et al. (2011). However, unlike the current study, Kinman et al. lumped together the two dimensions of emotional labour (surface acting and deep acting) to form a composite emotional labour score. Besides, Kinman et al. focused on the frequency of burnout experienced by teachers, whereas the current study focused on the intensity of burnout experienced by teachers.

Similarly, the current study found significant negative main effects of POS on the two dimensions of burnout (emotional exhaustion and depersonalization), thereby confirming hypotheses $2 \mathrm{a}$ and $2 \mathrm{~b}$. This suggests that enhancing perceived organizational support will protect teachers from burnout. This is consistent with the findings of Kinman et al. (2011) and Jawahar et al. (2007) who also reported an inverse association between workplace social support and emotional exhaustion and depersonalization among employees in human-service jobs.However, POS failed to moderate the associations between surface acting and emotional exhaustion; deep acting and emotional exhaustion; surface acting and depersonalization; and deep acting and depersonalization. Therefore, hypotheses $3 \mathrm{a}, 3 \mathrm{~b}, 3 \mathrm{c}$ and $3 \mathrm{~d}$ were not confirmed. Therefore, enhancing POS is unlikely to help teachers manage the emotional labour of the job more effectively in order to shield them from experiencing burnout. These findings are incongruence with the Job Demands-Resources (JD-R) model of burnout (Demerouti et al., 2001), that contends that job resources (e.g., social support) reduce the impact of job demands (e.g., emotional labour) on burnout. These findings are not in harmony with previous studies that found a moderating role of social support (e.g., Kinman et al., 2011; Moon et al., 2013). The findings were somewhat consistent with that of Jawahar et al. (2007) who found that POS failed to moderate the relations between perceived role conflict and depersonalization. It is possible that the measurement of POS unidimensionally may have to some extent, contributed to findings in the current study. Therefore, an assessment of the effect of different types of social support (e.g., informational, practical, appreciative and emotional; Prins et al., 2007) received from different 
sources at work (such as co-workers, supervisors, subordinates, managers, and administrators) can help to illuminate this process. It is also possible that a similar result could have been obtained like that of Kinman et al. (2011) and Moon et al. (2013) if the current study had also focused on the frequency of burnout experienced by teachers and not the intensity.

\subsection{Implications of Findings}

These findings illustrate the importance of this study for organizations, human resource (HR) managers, and career counsellors, as it gives insight into the impact of emotional labour and perceived organizational support (POS) on burnout. Hence, interventions are certainly vital to allay the negative impact of emotional labour in the teaching profession, and help teachers develop their emotion management skills. Seen in this light, helping employees develop strong emotional borders between work and home and make use of effective recuperation strategies may be beneficial (Kinman et al., 2011). This follows evidence that suggests that employees who are more proficient at detaching emotionally from work have greater protection from the unpleasant effect of emotional labour (Sonnentag, Kuttler, \& Fritz, 2009). Furthermore, given that the findings of the currents study revealed that not all aspects of emotional labour that teachers perform may be detrimental to their health, interventions designed to reduce surface acting and enhance deep acting may also be useful. Therefore, training to enhance emotional ability might be advantageous in helping teachers handle emotional labour and other types of stressors.

In addition, in order to minimize burnout, it is important for organizations to create job resources that are known to reduce burnout, such as organizational support. Therefore, interventions that cultivate organizational support might be particularly beneficial in decreasing burnout. It would even be preferable if different types and sources of organizational support are specified given that support is more likely to alleviate the impacts of a stressor if the particular type of support matchs up with the type of stressor (Cohen \& Wills, 1985). This would have the possibility to inform more exactly targeted interventions to help teachers address the issue of burnout in their job. Thus, interventions aimed at improving teacher support networks to increase group cohesiveness as well as the provision of emotional management counseling might be particularly beneficial (Kinman et al., 2011).

Also, the recommendation of Mann (2004) can be useful when implemented in the teaching profession. Mann underscores the importance of introducing policies and practices that engender the expression of emotion as a 'natural' part of the job. Mann went further to recommend that overarching programme that includes stress management techniques, debriefing and the encouragement of 'healthy catharses are likely to be helpful.

\subsection{Limitations of Study and Directions for Future Research}

As with all research, the current study has some limitations which need to be recognized. First, all data were obtained from the participants at one point in time, using self-report measures. Although it is essentially difficult in measuring emotion-related constructs more objectively, there is nonetheless a concern that the observed relationships could have been confounded by common method variance. However, attempt was made in the current study to lower the risk associated with common method variance by following Podsakoff, MacKenzie, Lee, and Podsakoff's (2003) approach by assuring the participants of their anonymity and confidentiality, encouraging them to be honest in their responses, and using scales of different response format. Future research should use other sources of data (e.g., official burnout complaints records, students' ratings of teachers' burnout manifestations etc.) to also address these concerns.

Another limitation is that the sample consisted only of secondary school teachers within a particular locality. This might limit the generalizability of the findings and the results to only secondary school teachers, as the representativeness of the sample may be questioned. Therefore, the generalization of the results to the entire working population must be done with caution. Thus, future researchers are advised to use a broader sample that cuts across several organizations in order to enhance generalizability.

In addition, the cross-sectional design of the study precludes causal inferences. This means that the relationships established in this study require further testing in longitudinal research. In other words, longitudinal studies are necessary to validate the findings of the current study. This is important since burnout may also partly be affected by coping ability and tolerance threshold.

Furthermore, the measurement of organizational support from only one dimension may have obscured the nuanced understanding of the impacts that different dimensions of organizational support would have had on burnout. Therefore, future researchers should measure different types (e.g., informational, practical, appreciative and emotional; Prins et al., 2007) and sources (e.g., co-workers, supervisors, subordinates, managers, and administrators) of organizational support in order to add to the robustness of their findings. 
Furthermore, the inclusion of data obtained from the use of qualitative methods such as in-depth interviews would have further enriched the findings in this study. Therefore, it would be remarkable if future research would include a qualitative examination of the processes proposed in this study.

\section{Conclusion}

This study gives insight into the impact that different components of emotional labour may have on different dimensions of burnout. The study demonstrated that whereas surface acting exacerbates emotional exhaustion among teachers, deep acting, and perceived organizational support on the other hand minimizes both emotional exhaustion and depersonalization. Human resource (HR) managers can utilize the knowledge derived from this study to promote a work setting that bolsters the probability of deep acting (rather than surface acting) and organizational support. Therefore, selecting for employees who are high in deep acting as well as providing them with necessary organizational support may result in teachers who are unlikely to suffer health impairment such as burnout. Surface acting is associated with emotional exhaustion, and those teachers who usually engage in surface acting are more likely to voluntarily turnover. In this sense, HR managers can screen out jobseekers that are more likely to engage in surface acting and suffer these adverse outcomes (Allen, Pugh, Grandey, \& Groth, 2010). The current study adds to the existing teachers' emotional labour and burnout research literature by focusing specifically on the intensity of burnout experienced by teachers in the Nigerian educational setting.

\section{References}

Allen, J. A., Pugh, S. D., Grandey, A. A., \& Groth, M. (2010). Following display rules in good or bad faith: Customer orientation as a moderator of the display rule-emotional labor relationship. Human Performance, 23(2), 101-115. http://dx.doi.org/10.1080/08959281003621695

Bakker, A. B., \& Demerouti, E. (2007). The job demands-resources model: State of the art. Journal of Managerial Psychology, 22(3), 309-328. http://dx.doi.org/10.1108/02683940710733115

Bakker, A. B., \& Heuven, E. (2006). Emotional dissonance, burnout and in-role performance among nurses and police officers. International Journal of Stress Management, 13(4), 423-440. http://dx.doi.org/10.1037/ 1072-5245.13.4.423

Bakker, A. B., Demerouti, E., \& Euwema, M. C. (2005). Job resources buffer the impact of job demands on burnout. Journal of Occupational Health Psychology, 10(2), 170-180. http://dx.doi.org/10.1037/1076-8998. 10.2.170

Bakker, A. B., Demerouti, E., \& Verbeke, W. (2004). Using the job demands-resources model to predict burnout and performance. Human Resource Management, 43(1), 83-104. http://dx.doi.org/10.1002/hrm

Bakker, A. B., Demerouti, E., De Boer, E., \& Schaufeli, W. B. (2003). Job demands and job resources as predictors of absence duration and frequency. Journal of Vocational Behavior, 62(2), 341-356. http://dx.doi.org/10.1016/S0001-8791(02)00030-1

Brotheridge, C. M. (2006). A review of emotional labour and its nomological network: Practical and research implications. Ergonomia IJE\&HF, 28(4), 295-309.

Brouwers, A., Tomic, W., \& Boluijt, H. (2011). Job demands, job control, social support and self-efficacy beliefs as determinants of burnout among physical education teachers. Europe's Journal of Psychology, 7(1), 17-39. http://dx.doi.org/10.5964/ejop.v7i1.103

Byrne, C. J., Morton, D. M., \& Dahling, J. J. (2011). Spirituality, religion, and emotional labor in the workplace. Journal of Management, Spirituality \& Religion, 4(8), 299-315. http://dx.doi.org/10.1080/14766086.2011. 630169

Chang, C. P., \& Chiu, J. M. (2009). Flight attendants' emotional labor and exhaustion in the Taiwanese airline industry. Journal of Service Science \& Management, 2(4), 305-311. http://dx.doi.org/10.4236/jssm.2009. 24036

Chang, M. (2009). An appraisal perspective of teacher burnout: Examining the emotional work of teachers. Educational Psychology Review, 21(3), 193-218. http://dx.doi.org/10.1007/s10648-009- 9106-y

Cohen, S., \& Wills, T. A. (1985). Stress, social support and the buffering hypothesis. Psychological Bulletin, 98(2), 310-357. http://dx.doi.org/10.1037/0033-2909.98.2.310

Çukur, C. Ş. (2009). The development of the Teacher Emotional Labor Scale (TELS): Validity and reliability. Educational Sciences: Theory \& Practice, 9(2), 559-574.

Demerouti, E. Bakker, A. B., Nachreiner, F., \& Schaufeli, W. B. (2001). The job demands- resources model of 
burnout. Journal of Applied Psychology, 86(3), 499-512. http://dx.doi.org/10.1037//0021-9010.86.3.499

Demerouti, E., Bakker, A. B., \& Leiter, M. (2014). Burnout and job performance: The moderating role of selection, optimization, and compensation strategies. Journal of Occupational Health Psychology, 19(1), 96-107. http://dx.doi.org/10.1037/a0035062

Doeglas, D., Suurmeijer, T., Briançon, S., Moum, T., Krol, B., Bjelle, A., \& Van den Heuvel, W. (1996). An international study on measuring social support: Interactions and satisfaction. Social Science \& Medicine, 43(9), 1389-1397.

Eisenberger, R., Huntington, R., Hutchison, S., \& Sowa, D. (1986). Perceived organizational support. Journal of Applied Psychology, 71(3), 500-507.

Fernet, C., Guay, F., Senécal, C., \& Austin, S. (2012). Predicting intraindividual changes in teacher burnout: The role of perceived school environment and motivational factors. Teaching and Teacher Education, 28(4), 514-525. http://dx.doi.org/10.1016/j.tate.2011.11.013

Grandey, A. A. (2000). Emotion regulation in the workplace: A new way to conceptualize emotional labor. Journal of Occupational Health Psychology, 5(1), 95-110. http://dx.doi.org/10.1037//1076-8998.5.1.95

Hebson, G., Earnshaw, J., \& Marchington, L. (2007). Too emotional to be capable? The changing nature of emotion work in definitions of 'capable teaching'. Journal of Education Policy, 22(6), 675-694. http://dx.doi.org/10.1080/02680930701625312

Heuven, E., \& Bakker, A. (2003). Emotional dissonance and burnout among cabin attendants. European Journal of Work and Organizational Psychology, 12(1), 81-100. http://dx.doi.org/10.1080/13594320344000039

Hobfall, S. E. (2001). The influence of culture, community, and the nested-self in the stress process: Advancing conservation of resources theory. Applied Psychology: An International Review, 50(3), 337-421. http://dx.doi.org/10.1111/1464-0597.00062

Hochschild, A. R. (1983). The managed heart: Commercialization of human feeling. Berkeley, CA: University of California Press.

Jawahar, I. M., Stone, T. H., \& Kisamore, J. L. (2007). Role conflict and burnout: The direct and moderating effects of political skill and perceived organizational support on burnout dimensions. International Journal of Stress Management, 14(2), 142-159. http://dx.doi.org/10.1037/1072-5245.14.2.142

Kinman, G., Wray, S., \& Strange, C. (2011). Emotional labour, burnout and job satisfaction in UK teachers: The role of workplace social support. Educational Psychology, 31(7), 843-856. http://dx.doi.org/10.1080/ 01443410.2011 .608650

Lee, D. C., Hung, L. M., \& Huang, S. C. (2012). Does job enjoyment and organizational support affect emotional labor? Journal of Business Research, 4(2), 5-29.

Mann, S. (2004). 'People work': Emotion management, stress and coping. British Journal of Guidance and Counselling, 32(2), 205-221. http://dx.doi.org/10.1080/0369880410001692247

Maslach, C., \& Jackson, S. E. (1981). The measurement of experienced burnout. Journal of Occupational Behaviour, 2(2), 99-113. http://dx.doi.org/10.1002/job.4030020205

Moon, T. W., Hur, W. M., \& Jun, J. K. (2013). The role of perceived organizational support on emotional labor in the airline industry. International Journal of Contemporary Hospitality Management, 25(1), 105-123. http://dx.doi.org/10.1108/09596111311290246

Mukundan, J., \& Ahour, T. (2011). Burnout among female teachers in Malaysia. Journal of International Education Research, 7(3), 25-38.

Ogińska-Bulik, N. (2005). The role of personal and social resources in preventing adverse health outcomes in employees of uniformed professions. International Journal of Occupational Medicine and Environmental Health, 18(3), 233-240.

Onyishi, I. E. (2006). Relationship between perceived organizational support and organizational citizenship behaviour in a Nigerian sample. Nigerian Journal of Psychological Research, 5, 37-51.

Podsakoff, P. M., MacKenzie, S. B., Lee, J. Y., \& Podsakoff, N. P. (2003). Common method biases in behavioral research: A critical review of the literature and recommended remedies. Journal of Applied Psychology, 88(5), 879-903. http://dx.doi.org/10.1037/0021-9010. 88.5.879

Prins, J. T., Hoekstra-Weebers, J. E., Gazendam-Donofrio, S. M., van de Wiel, H. B., Sprangers, F., Jaspers, F. C., 
\& van der Heijden, F. M. (2007). The role of social support in burnout among Dutch medical residents. Psychology, Health and Medicine, 12(1), 1-6. http://dx.doi.org/10.1080/13548500600782214

Rhoades, L., \& Eisenberger, R. (2002). Perceived organizational support: A review of the literature. Journal of Applied Psychology, 87(4), 698-714. http://dx.doi.org/10.1037/0021-9010.87.4.698

Sanz-Vergel, A. I., Rodríguez-Muñoz, A., Bakker, A. B., \& Demerouti, E. (2012). The daily spillover and crossover of emotional labor: Faking emotions at work and at home. Journal of Vocational Behavior, 81(2), 209-217. http://dx.doi.org/10.1016/j.jvb.2012.07.003

Schaufeli, W. B., \& Salanova, M. (2014). Burnout, boredom and engagement in the workplace. In M. C. W. Peeters, J. de Jonge, \& T. W. Taris (Eds.), An introduction to contemporary work psychology (1st ed.) (pp. 293-320). New York, NY: John Wiley.

Schaufeli, W. B., \& Taris, T. W. (2005). The conceptualization and measurement of burnout: Common ground and worlds apart. Work \& Stress, 19(3), 256-262. http://dx.doi.org/10.1080/02678370500385913

Schaufeli, W. B., \& Taris, T. W. (2014). A critical review of the job demands-resources model: Implications for improving work and health. In G. F. Bauer, \& O. Hämmig (Eds.), Bridging occupational, organizational and public health: A transdisciplinary approach (pp. 43-68). Dordrecht, Netherlands: Springer Science+Business Media. http://dx.doi.org/10.1007/978-94-007- 5640-3_4

Schaufeli, W. B., Bakker, A., \& van Rhenen, W. (2009). How changes in job demands and resources predict burnout, work engagement, and sickness absenteeism. Journal of Organizational Behavior, 30(7), 893-917. http://dx.doi.org/10.1002/job.595

Schaufeli, W., \& Enzmann, D. (1998). The burnout companion to study \& practice: A critical analysis. London, UK: Taylor \& Francis.

Sonnentag, S., \& Zijlstra, F. R. (2006). Job characteristics and off-job time activities as predictors of need for recovery, well-being, and fatigue. Journal of Applied Psychology, 91(2), 330-350. http://dx.doi.org/10.1037/ 0021-9010.91.2.330

Sonnentag, S., Kuttler, I., \& Fritz, C. (2009). Job stressors, emotional exhaustion and need for recovery: A multi-source study on the benefits of psychological detachment. Journal of Vocational Behavior, 76(3), 355-365. http://dx.doi.org/10.1016/j.jvb.2009.06.005

Srivastava, S. (2011). Job burnout and managerial effectiveness relationship: Moderating effects of locus of control and perceived organisational support: An empirical study on Indian managers. Asian Journal of Management Research, 2(1), 329-347.

Sutton, R. E. (2004). Emotional regulation goals and strategies of teachers. Social Psychology of Education, 7(4), 379-398. http://dx.doi.org/10.1007/s11218-004-4229-y

Van Gelderen, B. R., Konijn, E. A., \& Bakker, A. B. (2011). Emotional labor among trainee police officers: The interpersonal role of positive emotions. The Journal of Positive Psychology, 6(2), 163-172. http://dx.doi.org/10.1080/17439760.2011.558849

Zembylas, M. (2003). Emotions and teacher identity: A poststructural perspective. Teachers and Teaching: Theory and Practice, 9(3), 213-238. http://dx.doi.org/10.1080/13540600309378

\section{Copyrights}

Copyright for this article is retained by the author(s), with first publication rights granted to the journal.

This is an open-access article distributed under the terms and conditions of the Creative Commons Attribution license (http://creativecommons.org/licenses/by/3.0/). 